fa/tiny/news-3277503; in Farsi); (4) grant rangers permits to defend themselves in the event of attack by criminals (https://www.mehrnews.com/news/3694931/; in Farsi); and (5) where necessary, restrict access to important areas of cheetah habitat within protected areas, to hinder access for wildlife traffickers.

In addition, it is critical that other threats to Asiatic cheetahs are ameliorated. The most serious is collisions between cheetahs and vehicles (Diversity and Distributions, 2017, 23, 592-603), with 1-2 cheetahs killed on the roads annually (Cat News, 2007, 46, 8-11). To mitigate this threat we hope that the Department of the Environment will work with the Ministry of Roads and Urban Development to reduce roadkill rates, particularly at roadkill hotspots (bioRxiv, 2017, https://doi.org/10.1101/230581). We suggest a strategic shift in mitigation efforts away from the warning signs currently in use, as there is little evidence they are effective (PLoS One, 2016, 11, e0166941). Mitigation should instead focus on installing fencing in combination with wildlife crossing structures, as this approach is more effective at reducing roadkill rates (PLoS One, 2016, 11, e0166941), and crossing structures are frequently used by large carnivores (Frontiers in Ecology and Evolution, 2017, 5, 122; Wildlife Society Bulletin, 2017, 41, 712-719). We believe this strategy will be more successful in reducing collisions but it would require the full support of the Department of the Environment. To prevent the extinction of the Asiatic cheetah it is therefore critical that the Department makes cheetah conservation a top priority.

JAMSHID PARCHIZADEH Tehran City, Iran.

E-mail jamshid.parchizadeh@gmail.com

Maria GatTA School of Animal, Plant and Environmental Sciences, University of the Witwatersrand, Johannesburg, South Africa

ROBERTA BENCINI School of Animal Biology, The University of Western Australia, Crawley, Western Australia, Australia

Mohammad Ali Adibi Semnan Provincial Office of Iran Department of the Environment, Semnan Province, Iran, and Faculty of Environment and Energy, Department of Habitats and Biodiversity, Islamic Azad University, Science and Research Branch, Tehran City, Iran

Samual T. Williams Department of Zoology, School of Mathematical \& Natural Sciences, University of Venda, Thohoyandou, South Africa, and Department of Anthropology, Durham University, Durham, UK

\section{An action plan for marine turtle conservation in the Kingdom of Cambodia}

Sea turtles are flagship species for coastal and marine habitats in Cambodia and are categorized as Endangered Species under Cambodian Law. Among the sea turtle species found in Cambodia, the hawksbill turtle Eretmochelys imbricata is categorized as Critically Endangered on the IUCN Red List of Threatened Species and the green turtle Chelonia mydas as Endangered. Sea turtles are also listed on Appendix I of CITES, which bans international trade of these animals. In 2015 a Cambodian provincial consultation of coastal community members identified fishing, habitat degradation, coastal and island development, and pollution from solid waste and ghost nets as the main threats to sea turtles in Cambodia.

Because of their threatened status in Cambodia both national and international frameworks are now addressing the need to manage and conserve these species. Following consultation and review led by Fauna \& Flora International, Cambodia, and the Fisheries Administration of the Ministry of Agriculture, Forestry and Fisheries, the nation's first action plan for sea turtles was approved by the Director of General of the Fisheries Administration in October 2017.

This Sea Turtle National Action Plan for Cambodia (2016-2026) is a landmark step towards managing and conserving these threatened species. Protecting sea turtles and their threatened habitats in Cambodia will be achieved through the following complementary objectives: (1) reducing anthropogenic threats that cause mortality of sea turtles and their eggs, (2) protecting and rehabilitating sea turtle foraging and nesting grounds, (3) strengthening research and monitoring of sea turtle populations, foraging and nesting habitats, and bycatch reduction methods, (4) increasing public awareness of the threats to sea turtles and their habitats, and enhancing public participation in conservation activities, and (5) strengthening national and transboundary collaboration, and regional and international information sharing on sea turtles.

Fauna \& Flora International will take a leading role in supporting Cambodia's Fisheries Administration to deliver this action plan while coordinating Cambodia's Sea Turtle Network-a unique collective of private, public, community and NGO partners with a joint commitment to protect these charismatic marine species.

Rylida Vong, MarianNe TeOH and Kate West Fauna \& Flora International, Cambodia-Coastal \& Marine Conservation Project, Phnom Penh, Cambodia.

E-mail rylida.vong@fauna-flora.org 